\title{
Determining the Relationship between Counseling Needs and Employee's Age at Kenya Revenue Authority to Reduce Job Burnout
}

\author{
Esther Kerebi Nyamache ${ }^{1}$ Dr. Dennis Nyongesa Wamalwa Ph.D. ${ }^{2}$ \\ ${ }^{I}$ Ph.D. Student Faculty of Arts and Social Sciences in Counselling Psychology, The Catholic University of Eastern \\ Africa, Kenya, M.Ed. (Guidance and Counselling) Kenyatta university, Kenya. \\ ${ }^{2}$ Lecturer /Research Consultant; Ph.D., Department of Peace and Conflict Studies, Masinde Muliro University of \\ Science and Technology, Kenya, MA Counselling Studies, University of Manchester UK.
}

*Corresponding Author: Esther Kerebi Nyamache, Ph.D. Student Faculty of Arts and Social Sciences in Counselling Psychology, The Catholic University of Eastern Africa, Kenya, M.Ed. (Guidance and Counselling) Kenyatta University, Kenya.

\begin{abstract}
The study aimed at investigating the relationship between counseling needs and personal characteristics of age of Kenya KRA employees in reducing job burnout. The study utilized a survey research method with an application of descriptive research design. The study sample comprised of 60 employees from the five departments of Kenya Revenue Authority, Nairobi head office. The study targeted a total population of 1000 and the selection of the sample was done using stratified sampling techniques. The research used a questionnaire technique in data collection where a self-developed 25 item inventories of KRA employees counseling needs was designed and used to gather data. The study made use of descriptive design where both qualitative \& quantitative data was collected in order to determine correlate of counseling needs among the employees of KRA. Secondary data was sourced from organization records. The chi-square test was used to establish whether there is a relationship between employees counseling needs and their age. A $95 \%$ significance level (probability of 0.05) was utilized to determine the significance of the relationship. It was established that all employees require counseling services. It is hoped that these findings will generate information that aims to create understanding of counseling needs of employees to assist employers, HR managers and counselors to improve on employee wellbeing hence improve performance at workplace.
\end{abstract}

Keywords: Counselling Needs, Employees Age, Job Burnout, Relationship

\section{INTRODUCTION}

Employees are a common element and the most important resource in every institution and most important resource any organization can have. The employee's total well- being therefore, according to Nzuve (1997) is not only important to themselves but equally so to the employer. This is in agreement with Cooper's (1980) observation that the Human Relations School is founded on the assumption that people who are happy, satisfied with good mental health will make the most effective employees. Robbins (1996), concurs with the above studies by quipping that there are some stable individual attributes that affect experience in and reaction to the workplace. It is in view of these findings that UNESCO (2002), report indicates that due to the changing nature of work, there is need for workplace wellness. There is an increasing need to go beyond the factory model and create a workplace that is knowledge-driven with ample room for innovation, flexibility, and quality and customer service. Within this context, new working arrangements are being developed.

Locke (1976) asserts that for an organization to succeed, it must have contented workers; it is in recognition of this factor that prudent organizations place a high premium on their workers welfare. If the worker comfort in all the spheres mentioned above is not met, He or she experiences low job satisfaction and feels stressed. Lack of job satisfaction could lead to strikes, go-slows, absenteeism, high turnover, disciplinary problems, low productivity, health problems, and eventual burnout. Omondi 
(2009) has a view that workplace counseling is slowly finding its place at the workplace. It is important that those engaged as workplace counselors are accorded the necessary support to enable them deal with the workplace emerging issues. This can only be done if organizations such as Kenya Revenue Authority understand and embrace the underlying principles of staff wellness through counseling.

Kenya Revenue Authority is the government's body that collects the nation's revenue, income which is most often in the form of taxes. Part of the public assumes that the revenue officers to be hostile, malicious and arrogant, more especially when warnings are issued about deadlines of income tax returns. As a result, the researcher developed an interest to know if really these revenue officers have psychological needs and whether they require professional counseling. Specifically, the study aimed at determining whether there is any significant relationship between counseling needs and employee's age of KRA employees to reduce burnout. The employee's total well- being is not only important to themselves but equally so to the employer, (Amstrong2006).

\section{HYPOTHESIS}

The research formulated the following hypothesis

HO1: There is no relationship between the age of the employee and employee counseling needs.

\section{Methodology}

The study was treated to both quantitative and qualitative approach. After obtaining the required information from the questionnaires the data was coded for the analysis. This was done by studying closely the responses in each questionnaire. The data was grouped into tables for easier interpretations. The questionnaires were analyzed using frequency and percentages. Descriptive statistics were used to analyze the data collected. Further analysis involved testing the research hypothesis. Chi-square was used to test relationship between counselling needs and participant's needs.

\section{Participants}

The study sample comprised of 60 employees from the five departments of Kenya Revenue Authority, Nairobi head office. The study targeted a total population of 1000 and the selection of the sample was done using stratified sampling techniques.

\section{Age and Sex of the Respondents}

The distribution of the respondents by age is expressed in table 1:

Table1. Sex * Age (years) of the respondent cross tabulation

\begin{tabular}{|c|c|c|c|c|c|}
\hline & \multicolumn{2}{|c|}{ Sex of the respondent } & \multirow[t]{2}{*}{ AgeTotal } \\
\hline & & & Female & Male & \\
\hline & \multirow[t]{2}{*}{$25-30$} & Frequency & 10 & 14 & 24 \\
\hline & & $\%$ of Total & $16.7 \%$ & $23.3 \%$ & $40.0 \%$ \\
\hline & \multirow[t]{2}{*}{$31-35$} & Frequency Count & 7 & 9 & 16 \\
\hline & & $\%$ of Total & $11.7 \%$ & $15.0 \%$ & $26.7 \%$ \\
\hline & \multirow[t]{2}{*}{$36-40$} & Frequency & 5 & 5 & 10 \\
\hline & & $\%$ of Total & $8.3 \%$ & $8.3 \%$ & $16.7 \%$ \\
\hline & \multirow[t]{2}{*}{$41-45$} & Frequency & 8 & 1 & 9 \\
\hline & & $\%$ of Total & $13.3 \%$ & $1.7 \%$ & $15.0 \%$ \\
\hline & \multirow[t]{2}{*}{$45+$} & Frequency & 0 & 1 & 1 \\
\hline & & $\%$ of Total & $.0 \%$ & $1.7 \%$ & $1.7 \%$ \\
\hline \multirow{2}{*}{\multicolumn{2}{|c|}{ Total }} & Frequency & 30 & 30 & 60 \\
\hline & & $\%$ of Total & $50.0 \%$ & $50.0 \%$ & $100.0 \%$ \\
\hline
\end{tabular}

Results in table1 show $40 \%$ (24) of the respondents were ages between $25-35$ years. Out of these $16.7 \%$ were female while $23.3 \%$ were male. A summary of the respondent's age is given in figure 1 


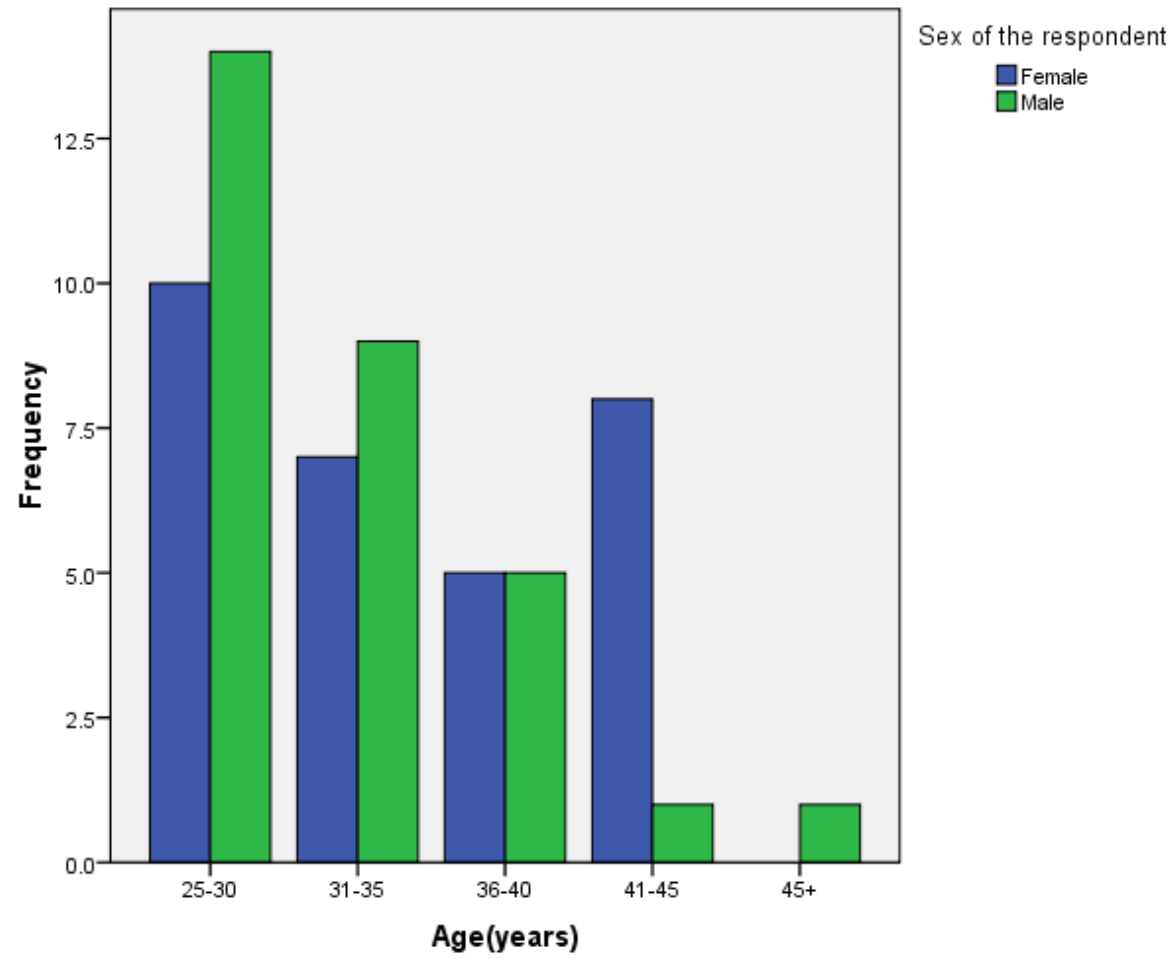

Figure1. Respondents age in years

\section{Procedure}

Inferential statistical analysis was done to test if there was any significant relationship between counselling needs of participant's age as stated in the hypothesis. Chi-square test was used to analyze the null hypothesis. For analysis, the probability level was set at 0.05 .

\section{Data Analysis}

\section{Hypotheses Testing}

HO1: There is no relationship between the age of the employee and employee counseling needs

Table2. Age and Employees' counselling needs

\begin{tabular}{|c|c|c|c|c|c|c|c|}
\hline \multirow{2}{*}{\multicolumn{2}{|c|}{ Problem }} & \multicolumn{6}{|c|}{ Age(years) } \\
\hline & & $25-30$ & $31-35$ & $36-40$ & $41-45$ & $45+$ & Total \\
\hline \multirow{2}{*}{$\begin{array}{l}\text { Family/marital } \\
\text { problems }\end{array}$} & $\mathrm{F}$ & 0 & 2 & 3 & 3 & 0 & 8 \\
\hline & $\begin{array}{l}\text { \% of } \\
\text { Total }\end{array}$ & $0.00 \%$ & $3.30 \%$ & $5.00 \%$ & $5.00 \%$ & $0.00 \%$ & $13.30 \%$ \\
\hline \multirow{2}{*}{$\begin{array}{l}\text { Work related } \\
\text { problems }\end{array}$} & $\mathrm{F}$ & 5 & 3 & 0 & 2 & 0 & 10 \\
\hline & $\begin{array}{l}\% \text { of } \\
\text { Total }\end{array}$ & $8.30 \%$ & $5.00 \%$ & $0.00 \%$ & $3.30 \%$ & $0.00 \%$ & $16.70 \%$ \\
\hline \multirow{2}{*}{$\begin{array}{l}\text { Health, safety } \\
\text { and welfare }\end{array}$} & $\mathrm{F}$ & 3 & 6 & 2 & 3 & 1 & 15 \\
\hline & $\begin{array}{l}\% \text { of } \\
\text { Total }\end{array}$ & $5.00 \%$ & $10.00 \%$ & $3.30 \%$ & $5.00 \%$ & $1.70 \%$ & $25.00 \%$ \\
\hline \multirow{2}{*}{$\begin{array}{l}\text { Alcoholism and } \\
\text { substance } \\
\text { dependence }\end{array}$} & $\mathrm{F}$ & 3 & 2 & 3 & 0 & 0 & 8 \\
\hline & $\begin{array}{l}\% \text { of } \\
\text { Total }\end{array}$ & $5.00 \%$ & $3.30 \%$ & $5.00 \%$ & $0.00 \%$ & $0.00 \%$ & $13.30 \%$ \\
\hline \multirow{2}{*}{$\begin{array}{l}\text { Personal issues } \\
\text { and challenge }\end{array}$} & $\mathrm{F}$ & 13 & 3 & 2 & 1 & 0 & 19 \\
\hline & $\begin{array}{l}\% \text { of } \\
\text { Total }\end{array}$ & $21.70 \%$ & $5.00 \%$ & $3.30 \%$ & $1.70 \%$ & $0.00 \%$ & $31.70 \%$ \\
\hline \multirow[t]{2}{*}{ Total } & $\mathrm{F}$ & 24 & 16 & 10 & 9 & 1 & 60 \\
\hline & $\begin{array}{l}\% \text { of } \\
\text { Total }\end{array}$ & $40.00 \%$ & $26.70 \%$ & $16.70 \%$ & $15.00 \%$ & $1.70 \%$ & $100.00 \%$ \\
\hline
\end{tabular}

A chi square test was done to test this hypothesis; the results are shown in table 3 
Determining the Relationship between Counseling Needs and Employee's Age at Kenya Revenue Authority to Reduce Job Burnout

Table3. Chi-Square Tests

\begin{tabular}{|l|c|c|c|}
\hline & Value & Do & Asymp.Sig.(2-sided) \\
\hline Pearson Chi-Square & $25.581^{\mathrm{a}}$ & & 16 \\
\hline
\end{tabular}

Results: $\chi^{2}=25.58, \mathrm{df}=16, \mathrm{p}=0.06, \mathrm{p}>0.05$. There is no significant relationship hence accept null hypothesis (Mugenda and Mugenda 2012).

Results in table 2: show that there is no significant relationship between age and employee's counseling needs. $\left(x^{2}=25.58, d f=16, p=0.06, p>0.05\right.$. Therefore, the null hypothesis is accepted.

\section{DISCUSSIONS}

The discussion of findings of the study is centered on the major research hypothesis directing the study: HO1 there is no significant relationship between counseling needs of employees and their age.

Information related to this was tabulated in table 2. The obtained chi-square statistics equals. The Asymp significant which is the probability of obtaining a chi-square value equal to or greater than

25.581 since the significance value is $>0.05$ this suggests that there is no significant relationship between employees counseling need and age.

The above result was also confirmed by Wakasiaka (2006), who said that there is no significant difference between age and counseling needs of employees at Mumias Sugar Company. These findings are in coloration with those carried out by Robbins, (2007) in His study on Organizational Behavior.

However, Kagure (2005), disagrees with the above finds and posits that age has a bearing on the level of stress generated by teaching matters while among those aged 25-29 none reported high stress, $28.6 \%, 16.7 \%$, and $12.5 \%$ reported stress among those aged 30-34,35-39, and 40 and above repeatedly. The older one becomes the greater the capability to manage and cope with stress as the study shows.

\section{CONCLUSIONS AND RECOMMENDATIONS}

With respect to research hypotheses investigated. It was found out that there is no significance relationship between age and counselling needs of employees. The study confirmed that there are general counseling needs in all types of areas studied among the employees of KRA. This implies that incase the organization wants to offer counseling services to its employees; the counseling program can be prepared to suit all employees regardless of their ages.

Therefore, the recommendation is that there is need for professional counseling services for the employees.

\section{RECOMMENDATIONS FOR FUTURE RESEARCH}

This study was carried out at Kenya Revenue Authority; a similar study is required in other types of companies across the globe.

\section{REFERENCES}

[1] Amstrong, M. (2006). A Handbook of Human Resource Management Practice. USA: Kogan Page Publishers.

[2] Cooper, C.L. (1980). Current Concerns in Occupational Stress. New York: John Wiley \& Sons Ltd.

[3] Kagure (2005). An Investigation into Causes of Teacher Stress in selected Public schools in Nairobi. Kenya: Kenyatta University. Nairobi.

[4] Locke, E.A. (1976). The Nature and Causes of Job satisfaction, A Handbook of Industrial and Organizational Psychology. Chicago IL: Rand McNelly.

[5] Mugenda, O.M and Mugenda, A.G. (2012). Research Methods: Quantitative Approaches, Nairobi ACTS Press.

[6] Omondi, D.A (2009). An Exploration into the Experience of Workplace Counselors and its Psychological Effects at the Workplace: A Case Study of Kenya Revenue Authority, Mombasa: KAPC.

[7] Robbins, S.P. (2007). Organizational Behaviour Pearson. New Jersey. Prentice Hall Inc

[8] Robbins, S.S. (1996). Organizational Behaviour U.S.A: Prentice Hall Inc.

[9] UNESCO (United Nations Educational Scientific and Culture Organizations) (2002). Technical and Vocational Education and Training in the $25^{\text {th }}$ Century, New Roles and Challenges for Guidance and Counseling. Paris; $7^{\text {th }}$ Place de Funtenoy T5352.

[10] Wakasiaka, F.J. (2006). An Investigation of Employee Counseling Needs among Non-Managerial Staff of Mumias Sugar Company, Kenya: Kenyatta University. 


\section{AUTHORS' BIOGRAPHY}

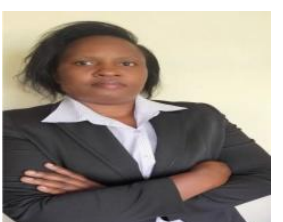

Nyamache E. Kerebi is a Ph.D. Student undertaking a course in counseling Psychology at The Catholic University of Eastern Africa. She is an Educator, a Counseling Psychologist, a Corporate Trainer and a Volunteer in humanitarian work. She teaches and lectures in Schools, colleges and organizations. She is a consultant in workplace counseling, mentoring and coaching. She is a Humanitarian Volunteer Worker at International Humanity Foundation, an Associate Counselor at Kenya Counselling and Psychological Association and an Associate Member of Institute of Human Resource Management. Nyamache holds a Master's degree in Education Psychology, Guidance and Counseling option and a Bachelor of Education (Arts) degree from Kenyatta University- Kenya. She possesses a Higher Diploma in Human Resource Management and has a Certificate in Workplace Counseling from the Institute of Human Resource Management

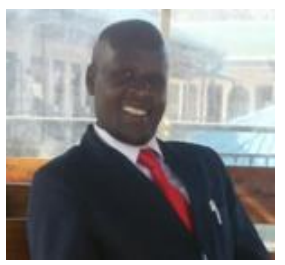

Dr. Dennis N. Wamalwa, is an associate research consultant with AFRIBA Research Consortium with the headquarter office based in Canada. He is a Lecturer, Trainer and Mental Health and Psychosocial well being consultant, with various International, National and Local NGOs, Cooperates, Government and Health Institutions for over 18 years. Registered member of Kenya Counsellors and Psychologists Association (Reg. No 0038/06 and accredited Counsellor Supervisor.

Dr. Wamalwa, holds a PhD in Peace and Conflict Studies from Masinde Muliro University of Science and Technology (MMUST) Kenya and a Masters of Arts in Counselling Studies, from The University of Manchester, (UK) coupled with numerous professional credentials. He has chaired presentations /defense panels and supervised of 20 postgraduate students' projects and theses to completion from various Universities, presented papers in National and International conferences and published over 16 research papers in refereed journals with high impact factor.

Citation: Esther Kerebi Nyamache \& Dennis Nyongesa Wamalwa."Determining the Relationship between Counseling Needs and Employee's Age at Kenya Revenue Authority to Reduce Job Burnout" International Journal of Humanities Social Sciences and Education (IJHSSE), vol 8,no.1, 2021, pp.1-5. doi:https://doi.org/ 10.20431/2349-0381.0801001.

Copyright: (C) 2021 Authors. This is an open-access article distributed under the terms of the Creative Commons Attribution License, which permits unrestricted use, distribution, and reproduction in any medium, provided the original author and source are credited. 